\title{
Epidemiologic Profile of an Otolaryngologic Emergency Service
}

\author{
Luciano Prestes $^{1}$ Rogerio Hamerschmidt ${ }^{2}$ Sergio Tenorio ${ }^{3}$ Ana Tereza Moreira ${ }^{4}$ Elizabeth Tambara ${ }^{5}$
}

1 Department of Emergency, IPO, Curitiba, Brazil

${ }^{2}$ Department of ENT, IPO, Curitiba, Brazil

${ }^{3}$ Department of Anesthesiology, UFPR, Curitiba, Paraná, Brazil

${ }^{4}$ Department of Ophthalmology, UFPR, Curitiba, Paraná, Brazil

${ }^{5}$ Department of Surgery, UFPR, Curitiba, Paraná, Brazil

\begin{abstract}
Address for correspondence Luciano Prestes, ENT, Department of Emergency, IPO, Av. República Argentina 2069, Curitiba 80620-010, Brazil (e-mail: lutiprestes@yahoo.com.br).
\end{abstract}

Int Arch Otorhinolaryngol 2014;18:380-382.

\begin{abstract}
Introduction According to current research, the number of patients seen in the emergency room is progressively increasing. There are few studies on the characteristics of ear, nose, and throat diseases treated in the emergency room.

Objectives (1) To establish the epidemiologic profile of patients with these complaints treated at a referral emergency hospital in locoregional city Curitiba, and (2) to evaluate the calls that truly required emergency care.

Methods This is a contemporary cross-study of urgent and emergency referrals to a hospital with otolaryngologic services during the year 2012. Data were collected and epidemiologic characteristics analyzed.

Results We analyzed 1,067 patients: 312 presented in spring, 255 in summer, 253 in autumn, and 247 in winter. We found 17 diseases that were common during the year, with 244 (23.99\%) upper respiratory tract infections being the most frequent disease. There was no statistically significant difference in the incidence of diseases, except that acute otitis media was most common during the summer $(p=0.02)$; distribution

\section{Keywords}

- emergency care

- epidemiologic studies

- ENT diseases between the sexes was balanced. The predominant age group was adults. We found $9.27 \%$ cases were true emergencies.

Conclusion Patients were 20 to 40 years, with upper respiratory tract infection the most incident disease; $9.27 \%$ of cases were emergencies.
\end{abstract}

\section{Introduction}

The epidemiologic profile of a particular disease can be expressed in absolute numbers (cases in a population at any given time) or characteristics over time. Knowledge of the incidence is important to learn if the disease occurs more or less in a given period. This is a determining factor in the guidance and direction of public, private, educational activities and research. Knowing the incidence aids in configuring and enabling global health care services, especially with respect to highly frequent diseases such as those seen in all age groups in outpatient clinics and emergency care in the field of otolaryngology. ${ }^{1}$

According to current research, the number of patients seen in urgent/emergency services is progressively increasing., ${ }^{2,3}$ This fact is repeated in national institutions, both public and private, according to the Brazilian Association of Otolaryngology and Cervical-Facial Surgery. In many open services, the subjectivity of the concept of urgency is detrimental to the proper care, because cases that are not true emergencies can overwhelm emergency rooms. The concept of urgency is variable, depending on social situations, family, employment, received

March 6, 2014

accepted

May 11, 2014

published online

June 17, 2014
DOI http://dx.doi.org/

10.1055/s-0034-1382099. ISSN 1809-9777.
Copyright $(2014$ by Thieme Publicações License terms Ltda, Rio de Janeiro, Brazil 
bureaucratic factors, and the patient's health and medical situations. $^{2}$

It is an internationally accepted fact that measurement of progress and scientific rigor of an area relates to the production of articles published in journals indexed and recognized as prestigious. There are few studies on the characteristics of ear, nose, and throat (ENT) diseases treated in emergency rooms, especially in relation to the severity of treated cases and the adequacy of assistance by the institutions providing care. ${ }^{4}$ Timsit et al reported that only $10 \%$ of cases presenting to an emergency room were true emergencies. ${ }^{5}$

Pino Rivero et al, in work developed from data on ENT emergencies, affirm that it is essential to define frameworks for what constitutes an actual emergency so as to enable adequate planning and care. ${ }^{6}$ They also consider that fewer than one third of the visits could be considered real emergencies.

A literature review of studies of the incidence of ENT diseases included searches in VHL (Virtual Health Library), which uses as a database Lilacs; IBEC; Medline; BBO; CidSaúde; DISASTERS; MedCarib; REPIDISCA; BDENF HOMEOINDEX; PAHO; and WHOLIS Cochrane Library. Of the 97 studies found, only three are Brazilian, and of these, two are limited to pediatrics and the third to geriatrics. ${ }^{5}$

The objectives of this study are:

1. Establish the annual epidemiologic profile of patients with these complaints treated in a hospital in the city of Curitiba.

2. Evaluate the cases that really would require emergency care.

\section{Methods}

This study design was chosen because of its ability to identify possible risk factors associated with ENT diseases, mainly to factors that remain unchanged over time and that may provide valid evidence of statistical associations, without defining the etiologic character. Moreover, it was low cost, with a high description potential and analytical simplicity.

We statistically analyzed appropriate factors according to the nature of the data. Inferential statistics were compared for the year 2012 on the following variables: sex, age, upper respiratory tract infections (URTIs), acute rhinosinusitis, tonsillitis, acute rhinitis, cerumen, acute otitis media, acute otitis externa, epistaxis, vertigo, acute laryngitis, secretory otitis media, peritonsillar abscess, temporomandibular joint dysfunction, tinnitus, nasal fracture, nasal foreign body, and foreign body in the ear. For this, we used the standard analysis $\left(\mathrm{X}^{2}\right)$ test with significance level $\alpha<0.05$. Graphs of annual frequency of high and low incidence diseases were developed.

\section{Results}

Data from 1,067 patients were collected from January 1, 2012, to December 21, 2012. During the spring, a total of 312 patients were seen. Of them, 179 (57.37\%) were female, and $30.98 \%$ were in the age group 20 to 40 years. During the summer, a total of 255 patients were seen. There was no

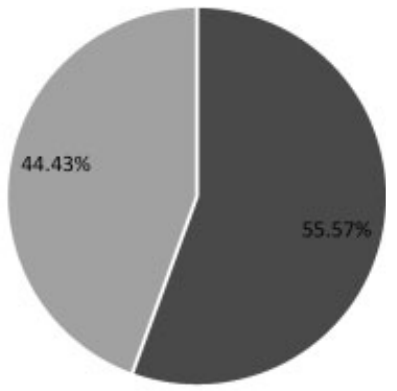

- F - $593 \quad=\mathrm{M}-474$

Fig. 1 Patients by gender $(n=1,067)$.

significant difference between females ( $n=132 ; 51.76 \%$ ) and males $(n=123 ; 48.24 \%)$ in the emergency service. In summer, $38.32 \%$ of patients were in the age group 20 to 40 . During the fall, a total of 253 patients were seen; 143 (56.2\%) patients were female and 110 patients (43.48\%) were male. In the fall, $36.41 \%$ of patients were in the age group 20 to 40 years. During the winter, a total of 247 patients were seen; 139 (56.28\%) patients were female and 108 patients ( $43.72 \%$ ) were male. In winter, $42.34 \%$ of patients were in the age group 20 to 40 years.

-Fig. 1 shows the distribution of patients by gender throughout the year. We found a higher incidence of females (55.57\%). We evaluated the correlation between sex and seasons to demand emergency service through standard analysis $\left(\mathrm{X}^{2}\right)$ testing. There was no statistically significant difference between them. - Fig. 2 shows the attendance by age throughout the year. Overall, $37.01 \%$ of patients were in the age group 20 to 40 years.

The most common diseases during the study period were (in descending order): URTIs ( $n=262 ; 24.55 \%$ ), acute rhinosinusitis (RSA; $n=173 ; 16.21 \%)$, tonsillitis $(n=135$; $12.65 \%)$, acute rhinitis $(n=80 ; 7.49 \%)$, cerumen $(n=74$; $6.93 \%$ ), acute otitis media (AOM; $n=72 ; 6.84 \%$ ), acute otitis externa ( $n=62 ; 5.81 \%)$, epistaxis $(n=53 ; 4.96 \%)$, vertigo ( $n=42 ; 3.93 \%)$, acute laryngitis $(n=31 ; 2.90 \%)$, secretory otitis media ( $n=25 ; 2.34 \%$ ), peritonsillar abscess ( $n=25$; $2.34 \%)$, temporomandibular joint dysfunction $(n=18$; $1.68 \%)$, tinnitus $(n=13 ; 1.21 \%)$, nasal fracture $(n=9$; $0.84 \%$ ), nasal foreign body $(n=6 ; 0.56 \%)$, foreign body in the ear $(n=6 ; 0.56 \%)$. - Fig. 3 shows the distribution of the five most common diseases during the year, accounting for $67 \%$ of total attendance.

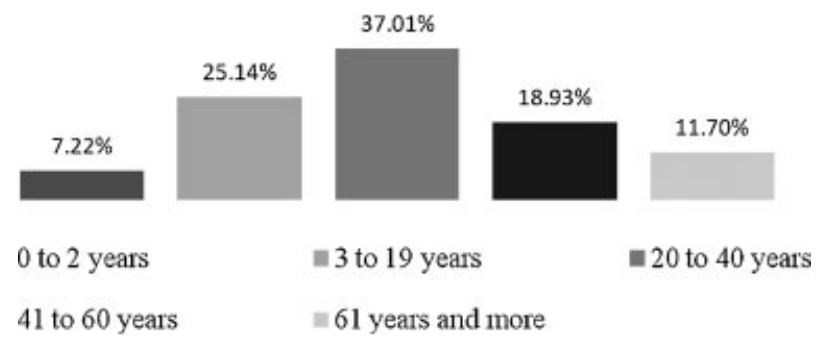

Fig. 2 Patients by age group $(n=1,067)$. 


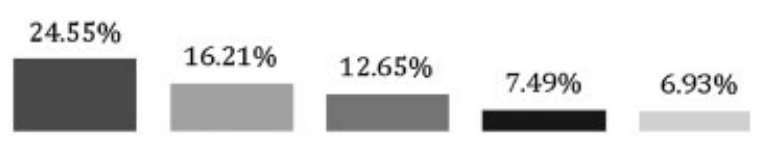

\section{URTI $\approx$ RSA $\approx$ Tonsilitis $\square$ Acute Rhinitis $\approx$ Cerumen}

Fig. 3 Most common diseases $(n=1,067)$. Abbreviations: RSA, acute rhinosinusitis; URTI, upper respiratory tract infection.

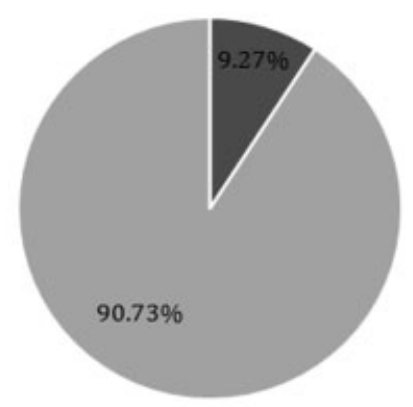

- Emergency " Routine

Fig. 4 Emergency and routine cases $(n=1,067)$.

We apply the standard analysis $\left(\mathrm{X}^{2}\right)$ test among the most common diseases in relation to the seasons and found an increased incidence of AOM in the summer compared with other seasons $(p=0.02)$. With other diseases, there was no significant difference in frequency in relation to the seasons of the year.

Among the most common diseases, epistaxis, peritonsillar abscess, nasal fracture, nasal foreign body, and foreign body in the ear were considered true emergencies. In all, 99 (9.27\%) true emergencies were noted ( $\mathbf{- F i g . ~ 4 ) . ~}$

\section{Discussion}

The flow of ENT patients in Curitiba is intense during all seasons of the year; with the epidemiologic profile of emergency room cases, we can develop strategies to better serve our patients. In addition, studies on the epidemiologic profile in otolaryngology are scarce, which makes this type of study necessary for our medical specialty.

We found that the demand for ENT care is higher in female patients; however, there was no statistically significant dif- ference between the sexes. The most common age group in all seasons was 20 to 40 years. This demonstrates that our patients are mostly adults. When considering that this age group is the most economically active, removals and medical certificates must be made judiciously. Among the most common diseases, URTI and RSA were the most frequent throughout the year.

We also conclude that our service is primarily composed of urgency care, and only 99 (9.27\%) cases were considered real emergencies. Timsit et $\mathrm{al}^{5}$ found in their series that $10 \%$ of cases were considered emergencies, close to the value found in our city.

In future studies, we will continue to evaluate the incidence of disease in each age group as well as the most commonly prescribed drugs in our service.

\section{Conclusion}

1. The patients profile was successfully made: 20 to 40 years old, cases of urgency, with upper respiratory tract infection the most common disease.

2. We found an incidence of $9.27 \%$ of true emergency cases in emergency care of otolaryngology in Curitiba.

\section{References}

1 ABORL-CCF. Projeto Epidemiológico 2012. São Paulo, Brazil: Associação Brasileira de Otorrinolaringologia e Cirurgia Cérvico-facial; c2003-2014. Available at:http://www.aborlccf.org.br/epidemiologico/regioes.asp Accessed in Jan 1, 2014.

2 Lunedo SMC, et al. The prevalence of the major ENT symptoms in an ambulatorial geriatric population. Arq Int Otorrinolaringol 2008;12(1):95-98

3 Gallo A, Moi R, Minni A, Simonelli M, de Vincentiis M. Otorhinolaryngology emergency unit care: the experience of a large university hospital in Italy. Ear Nose Throat J 2000;79(3): $155-158,160$

4 Cheng TP, Weckx LLM. Atendimento otorrinolaringológico do Sistema Único de Saúde de crianças e adolescentes em três municípios brasileros. Rev Bras Otorrinolaringol (Engl Ed) 2008; 74(4):571-578

5 Timsit CA, Bouchene K, Olfatpour B, Herman P, Tran Ba Huy P. Étude épidémiologique et clinique portant sur 20563 patients accueillis à la grande garde d'urgences ORL adultes de Paris Ile-deFrance. Ann Otolaryngol Chir Cervicofac 2001;118(4):215-224

6 Pino Rivero V, Trinidad Ruiz G, González Palomino A, et al. Considerations about ENT emergencies. Analysis of 30,000 patients assisted in 10 years. Acta Otorrinolaringol Esp 2005;56(5): 198-201 